\title{
Towards healthy and sustainable food consumption: an Australian case study
}

\author{
Sharon Friel ${ }^{1, *}$, Laurel J Barosh ${ }^{1}$ and Mark Lawrence ${ }^{2}$ \\ ${ }^{1}$ National Centre for Epidemiology and Population Health, Australian National University, Canberra, ACT 0200, \\ Australia: ${ }^{2}$ Population Health Strategic Research Centre, Deakin University, Melbourne, Australia
}

Submitted 15 November 2012: Final revision received 10 April 2013: Accepted 8 May 2013: First published online 13 June 2013

\begin{abstract}
Objective: To articulate a healthy and sustainable (H\&S) diet; outline key health and environmental sustainability principles that can be applied in the selection of foods for inclusion in such a diet; and describe a methodology with which to assess the availability and affordability of a H\&S food basket.

Design: We synthesized publically available evidence on the environmental impact of different foods from academic, government, industry and non-government sources and constructed a hypothetical H\&S equivalent of the typical Australian diet. Based on this, we constructed a weekly H\&S food basket for a household of two adults and two children.

Setting: Australia.

Subjects: Australian populations.

Results: The H\&S diet is based on three overarching principles: (i) any food that is consumed above a person's energy requirement represents an avoidable environmental burden in the form of greenhouse gas emissions, use of natural resources and pressure on biodiversity; (ii) reducing the consumption of discretionary food choices, which are energy-dense and highly processed and packaged, reduces both the risk of dietary imbalances and the use of environmental resources; and (iii) a diet comprising less animal- and more plant-derived foods delivers both health and ecological benefits.

Conclusions: We have focused on the articulation of a H\&S diet not to facilitate 'policy drift' to focus on individual dietary choice, but rather to provide evidence to extend dietary guideline recommendations so as to integrate environmental considerations within the scope of food and health policy advice in Australia and elsewhere.
\end{abstract}

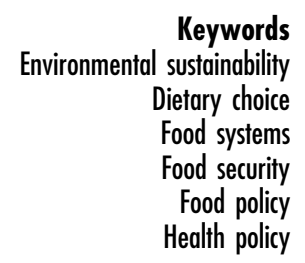

Food insecurity is an important health concern worldwide and in Australia, with growing recognition that existing differentials in the availability, accessibility and affordability of nutritious food between and within nations are being intensified by environmental change ${ }^{(1-4)}$. The relationship between environmental change, food systems and food security is dynamic and bidirectional. The functioning of the food system, in terms of food yields, safety and nutritional quality, can be affected by environmental change ${ }^{(5)}$. At the same time, one of the major contributing factors to environmental change is the processes and outputs from the food system ${ }^{(6)}$. Given the very real environmental constraints, there is a need for food supply and consumption strategies in all regions of the world that ensure food security without further jeopardizing the environment.

Conventionally, dietary guidelines have focused on providing information on the types and amounts of foods, food groups and dietary patterns that aim to promote health and well-being, as measured in terms of risk of diet-related conditions and chronic disease ${ }^{(7)}$. Around the world, including Australia, the importance of integrating environmental considerations into people's food choices is now recognized as an important component of a policy response concerned with health, food security and environmental sustainability ${ }^{(8-19)}$. Sustainable diets have been defined as: 'those diets with low environmental impacts which contribute to food and nutrition security and to healthy life for present and future generations. Sustainable diets are protective and respectful of biodiversity and ecosystems, culturally acceptable, accessible, economically fair and affordable; nutritionally adequate, safe and healthy; while optimizing natural and human resources, ${ }^{\text {(11) }}$. As yet however there is no consensus in Australia, or elsewhere, as to what a healthy and sustainable (H\&S) diet might look like and therefore no policy advice to support the implementation of actions to enable people and institutions make H\&S food purchasing and consumption choices. 
While the total environmental impacts of individual foods are often difficult to measure and the technical endeavours to do so are still relatively new, there is, we believe, sufficient evidence to begin to outline an H\&S diet. The aim of the present paper is to use existing evidence to describe a hypothetical H\&S diet and a methodological approach to assess its availability and affordability. The paper briefly outlines the relationship between environmental change and food systems. It lays out the argument for changing food consumption habits as one part of a policy response to promote health while at the same time reducing environmental damage. In the remainder of the paper we describe the methods to construct a hypothetical H\&S diet.

\section{The relationship between environmental change and the food system}

Climate change-related drought-prone and long-term drying conditions in sub-tropical regions, higher temperatures, rising sea levels, increasing frequency of flooding and acidification of oceans are now beginning to contribute to impaired yield, quality and affordability of food in many countries $^{(3,6,20-22)}$. Fresh water supplies are shrinking, with half the world's rivers seriously depleted and polluted. Biodiversity, the basis of ecosystem services, has been more seriously harmed through human activities in the last 50 years than at any other period ${ }^{(20)}$.

The food system - from agricultural production, food processing and packaging, distribution and retail to consumption - produces not only food for consumption but also outputs that are returned to the natural environment, including greenhouse gases (GHG), packaging and food waste. Each of these outputs can contribute to environmental degradation $^{(6)}$, the extent of which depends on the inputs (land, water, energy) and processes used in production, the region of production and seasonal variations.

There is a growing body of life cycle analysis (LCA) research relating to GHG emissions, water use and biodiversity and the Australian food system. LCA is a method of quantifying the environmental impact of a product over its life cycle and is the most common tool for analysing the impact of a food system (or part thereof) on the environment.

\section{Greenbouse gas emissions}

In 2010 , agricultural production contributed $18 \cdot 8 \%$ to Australia's overall GHG emissions ${ }^{(23)}$. The major contributor to agricultural emissions is livestock, due to the significant production of the highly potent GHG methane. GHG emissions also come from other agricultural sources, such as nitrogen fertilizer and energy use in irrigation and other on-farm inputs. GHG emissions also occur at other parts of the food supply chain, such as processing, distribution, packaging, storage, cooking and waste ${ }^{(24)}$.

\section{Water use}

In 2004-05, irrigated agriculture accounted for 65\% of Australia's water use, compared with 9\% from urban and industrial consumption ${ }^{(25)}$. According to the State of the Environment report (2011), large areas of Australia, both urban and rural, are using groundwater above a sustainable level ${ }^{(26)}$. High use of irrigation can lead to shallow water tables, salinity and water-logging ${ }^{(27-29)}$. Water is used in other parts of the food system, for example in cleaning and washing while processing the food product or as an input into the final product ${ }^{(30,31)}$.

\section{Biodiversity}

Agriculture, by necessity, involves an altering of natural vegetation and as a result production in agriculture systems has an impact on land and water on and around the farm, with consequences for native biodiversity. The introduction of exotic species and land clearing lead to increased vulnerability to pests, changes in climate, habitat loss and destruction, and overall biodiversity decline ${ }^{(32)}$.

\section{The basis of a healthy and sustainable diet}

The H\&S diet presented herein is not being posed as the definitive diet but rather an attempt to introduce principles of environmental sustainability into research on food and health and thereby ultimately help integrate environmental considerations into food and health policy, especially dietary guideline advice. The H\&S diet was developed first according to health principles and constructed around the conventional health focus of the Australian Dietary Guidelines (ADG), described in Box $1^{(8)}$.

The sustainability of the H\&S diet was informed using a review of publically available evidence from academic, government, industry and non-government sources describing the environmental impact of the food system on GHG emissions, water use and biodiversity in Australia $^{(33)}$ plus other relevant international reports and peer-review publications ${ }^{(3,6,34-41)}$. The published evidence focuses largely on particular foods and food groups and on the primary production phase of the food system. The activities around pre-farm processes (such as fertilizer and machinery production) and post-farm product processing were also identified, although not to the same extent as on-farm activities.

\section{Overconsumption: not good for bealth, not good for the environment}

Guideline 1 of the ADG recommends consumption of nutritious food and drinks ('five food groups foods') to meet a person's energy needs and is based on the evidence that overconsumption of food is associated with obesity and non-communicable diseases. In addition, any food that is consumed above a person's energy requirements represents avoidable GHG emissions, use of natural resources and pressure on biodiversity. 
Box 1 Australian Dietary Guidelines (ADG)

ADG1. To achieve and maintain a healthy weight, be physically active and choose amounts of nutritious food and drinks to meet your energy needs.

ADG2. Enjoy a wide variety of nutritious foods from these five groups every day:

- Plenty of vegetables, including different types and colours, and legumes/beans.

- Fruit.

- Grain (cereal) foods, mostly wholegrain and/or high cereal fibre varieties, such as breads, cereals, rice, pasta, noodles, polenta, couscous, oats, quinoa and barley.

- Lean meats and poultry, fish, eggs, tofu, nuts and seeds, and legumes/beans.

- Milk, yoghurt, cheese and/or their alternatives, mostly reduced-fat (reduced-fat milks are not suitable for children under the age of 2 years).

And drink plenty of water.

ADG3. Limit intake of foods containing saturated fat, added salt, added sugars and alcohol.

a. Limit intake of foods high in saturated fat such as many biscuits, cakes, pastries, pies, processed meats, commercial burgers, pizza, fried foods, potato chips, crisps and other savoury snacks.

- Replace high-fat foods which contain predominantly saturated fats such as butter, cream, cooking margarine, coconut and palm oil with foods which contain predominantly polyunsaturated and monounsaturated fats such as oils, spreads, nut butters/pastes and avocado.

- Low-fat diets are not suitable for children under the age of 2 years.

b. Limit intake of foods and drinks containing added salt.

- Read labels to choose lower-sodium options among similar foods.

- Do not add salt to foods in cooking or at the table.

c. Limit intake of foods and drinks containing added sugars such as confectionery, sugar-sweetened soft drinks and cordials, fruit drinks, vitamin waters, energy and sports drinks.

ADG4. Encourage, support and promote breast-feeding.

ADG5. Care for your food; prepare and store it safely.

Guideline 3 of the ADG recommends limiting the intake of foods containing saturated fat, added salt and added sugars. Described as 'discretionary' food choices, where discretionary choices are foods and drinks not necessary to provide the nutrients the body needs ${ }^{(7)}$, these foods tend to be highly processed (e.g. biscuits, crisps, sugar-sweetened beverages) ${ }^{(42)}$. The adverse health and environmental outcomes described in the previous paragraph are especially pronounced when highly processed foods are overconsumed: these foods are generally energy-dense and nutrient-poor and can readily contribute not only to excessive energy intake, but also nutritional imbalances ${ }^{(39)}$. Although few discretionary food choices have been analysed for their environmental impact across the life cycle, as they are typically highly processed food products they are very likely to use relatively more environmental resources in their production than less-processed foods and have the risk of more environmental outputs. Therefore, their negligible contribution to nutrient intake means that the environmental cost of providing such foods is not offset by a positive compensatory health outcome.

\section{Environmental impact of foods}

A description of the evidence associated with the environmental impact within the five food groups recommended in Guideline 2 of the ADG is given below.
Vegetables, including different types and colours, and legumes/beans

Compared with animal foods, emissions from vegetables are lower, both overall and on a unit weight basis. Most emissions from vegetables come from electricity use in irrigation, soil fertilizer and post-harvest on-farm activities such as cooling, refrigerating, cleaning and packaging the product $^{(43)}$. On a per tonne basis, potatoes, lettuce and tomatoes have relatively low emissions ${ }^{(43)}$. While $86 \%$ of the area of Australia's vegetable crops is under irrigation, water use for production of vegetables is lower than that for animal-based foods, although there is great variation between $\operatorname{crops}^{(44)}$. Evidence indicates that asparagus, celery and garlic are among the least water efficient, while carrots, lettuce and tomatoes are among the most water efficient ${ }^{(45-52)}$. There was no Australian evidence available for the environmental impact of legumes/beans.

\section{Fruit}

Little Australian information is available on the environmental impact of fruit, with the analyses that exist focusing most on water use. Fruit crops in Australia are highly dependent on irrigation water, with $74 \%$ of the area sown to fruit trees, nut trees and plantation of berry fruits under irrigation $^{(44)}$. While not conclusive, studies suggest that pineapples are most water efficient, and avocadoes and mangoes are least water efficient ${ }^{(53,54)}$. Other fruit crops, 
such as strawberries and pome fruit (apples and pears), are very similar in their water use efficiency. In the fruit (and vegetable) products sector, which includes processing of fruits and vegetables and produces a wide range of frozen, dried, canned and partly prepared products (fruit juices, frozen vegetables, preserved fruit, sauces and jams), GHG emissions are 5\% below the food sector average, land disturbance is $35 \%$ below average and water use is over twice the average ${ }^{(55)}$.

\section{Grain (cereal) foods, mostly wholegrain and/or high} cereal fibre varieties, such as breads, cereals, rice, pasta, noodles, polenta, couscous, oats, quinoa and barley An increasing number of LCA have considered Australian cereal crops ${ }^{(56,57)}$. Most analysis is focused on the primary production process. Of the GHG emissions from cereals, only those for wheat and rice are known, with emissions from one tonne of rice lower than emissions from one tonne of wheat and lower than emissions from meat and dairy ${ }^{(58)}$. Despite a lower reliance on irrigated water (about $1.4 \%$ of the area planted to cereal crops for grain or seed is irrigated) ${ }^{(44)}$, the evidence suggests that water use for cereals is higher than for fruit and vegetables, while still being lower than for animal-source foods. Results vary for each crop depending on irrigation; however, using those studies that can be compared, on average rice was found to be the least water efficient. Wheat was the next least water efficient, followed by barley and oats ${ }^{(56,57)}$. Little information exists on biodiversity issues, with the exception of rice, which due to its highly irrigated nature ${ }^{(44)}$ has associated issues such as rising water tables, salinization and water-logging ${ }^{(59)}$.

Lean meats and poultry, fish, eggs, tofu, nuts and seeds, and legumes/beans

Most evidence in this group is based on the primary production stage of the food system. Compared with other foods in this group, beef and lamb production has a relatively large negative impact on the environment through GHG emissions, water use and pressure on biodiversity. Together, beef cattle and sheep account for around $80 \%$ of Australia's agricultural emissions ${ }^{(60)}$. The enteric fermentation process by ruminant animals is by far the biggest contributor to carbon dioxide equivalent emissions from the agriculture sector in Australia $(57 \cdot 6 \mathrm{Mt}$ $\mathrm{CO}_{2}$-e in 2007) ${ }^{(60,61)}$. On a unit basis, the available evidence suggests that cattle, followed by sheep, have the highest level of emissions per unit weight ${ }^{(58,61,62)}$. Although little quantitative evidence exists, increasing consumption of kangaroos, being non-ruminant forestomach fermenters that produce negligible amounts of methane relative to cattle and sheep, may help lower Australia's GHG emissions ${ }^{(63)}$. Water use in the production of meat is highly dependent on the use of irrigated feed: water use of a supply chain that purchased irrigated feed was fifteen times higher than that of a supply chain not relying on irrigation ${ }^{(64)}$. Beef and lamb production is thought to exert greater pressure on biodiversity compared with other meats such as goat, kangaroo, pork and poultry. In particular, extensive beef and lamb production have a greater biodiversity impact than feedlot production $^{(65)}$. Aquaculture-produced fish is considered to have a greater negative impact on biodiversity than wild catch fish ${ }^{(65)}$. A major environmental concern for the fishing industry is the overfishing of some species. Although there have been improvements, thirteen fish stocks were classified as overfished in $2009^{(66)}$.

\section{Milk, yoghurt, cheese and/or their alternatives, mostly reduced-fat}

The primary production stage accounts for about $85 \%$ of emissions from the dairy food industry, uses large quantities of water in irrigation and exerts significant pressures on biodiversity ${ }^{(65,67-69)}$. The majority of on-farm emissions from dairy production are enteric methane emissions, although the exact proportion varies depending on the study (from $48 \%$ to $55 \%^{(70,71)}$ ). The dairy industry is the largest user of irrigation water in Australia, predominantly in the production of feed for dairy cattle which uses $40 \%$ of water diverted for irrigation ${ }^{(27,29,67)}$. Overall, the dairy industry exerts a similar degree of pressure on the environment as feedlot beef: not as significant as extensive beef production, but greater than the production of meats such as lamb, kangaroo, pork and chicken ${ }^{(65)}$. At the processing stage, one tonne of yoghurt and one tonne of cheese produce approximately 1.4 and 5.7 times the GHG emissions in one tonne of milk ${ }^{(67)}$. Water use is lower in the production of one tonne of milk, with one tonne of yoghurt requiring about twice as much water as milk and one tonne of cheese requiring $9 \cdot 3$ times more water than milk ${ }^{(72)}$.

The balance of the evidence across the five food groups indicates that plant-based foods in general have a lower environmental footprint than animal-source foods. There is substantial variation in the environmental impact within each of the food groups, with not all foods having any or comparable environmental impact analysis.

\section{Health and sustainability principles}

Combining the health and environmental impact evidence, three guiding principles were applied when developing the H\&S diet.

1. Any food that is consumed above a person's energy requirement represents an avoidable environmental burden in the form of GHG emissions, use of natural resources and pressure on biodiversity.

2. Reducing the consumption of discretionary food choices, which are energy-dense and highly processed and packaged, reduces both the risk of dietary imbalances and the use of environmental resources.

3. A diet comprising less animal- and more plant-derived foods delivers both health and ecological benefits. 


\section{Operationalizing a healthy and sustainable diet - a food basket approach}

In the present study we expand the traditional 'food basket' approach to include environmental considerations thereby creating an environmentally friendly and healthy food basket. The food basket approach is one of the most commonly used and recognized methods for assessing and monitoring food availability and cost, internationally ${ }^{(73,74)}$ and within Australia ${ }^{(75-77)}$. Two baskets were developed: one reflecting a typical diet and one that incorporated principles of health and environmental sustainability. Each food basket was constructed to reflect the weekly food purchasing of a hypothetical reference household, in this instance an adult male (aged 19-60 years), an adult female (aged 19-60 years), a boy aged 15 years and a girl aged 4 years. Foods included in the basket were selected in accordance with the three food choice categories listed in the Australian Guide to Healthy Eating: (i) the five food groups category; (ii) the allowance for unsaturated spreads and oils category; and (iii) the discretionary food choices category.

\section{'Typical diet' basket}

The reference household's habitual food consumption patterns were identified using the most recent national nutrition survey data (1995 National Nutrition Survey). The patterns observed in 1995 National Nutrition Survey were cross-checked using the most recent (at the time of study development) household expenditure data (Australian Bureau of Statistics 2003-04). Based on these typical consumption habits, $7 \mathrm{~d}$ meal plans were constructed to provide a framework for the selection of foodstuffs for inclusion in the weekly food basket. Meal plans consist of breakfast, lunch, dinner and snacks for Monday through to Sunday. The construction of meal plans helps estimate the quantities of foods that need to be purchased for the week (e.g. one litre of milk) and are based only on at-home consumption. All food items contained in the meal plans were aggregated into one list thereby constructing a typical weekly food basket.

\section{'Healtby and sustainable diet' basket}

The H\&S food basket was constructed using an adapted version of the food items included in the meal plans of the typical food basket. The food items were replaced to reflect the health and environmental sustainability principles described previously, and foods were chosen that had a lower environmental impact as identified in the Australian evidence base ${ }^{(33)}$. The H\&S meal plans were developed to be consistent with the minimum recommended servings for that food group in the ADG.

Table 1 summarizes the decision logic that was used to replace the 'typical diet' foods with healthy and sustainable foods. For example, in the 'meat, fish, eggs, legumes, nuts' food group, quantities of red meat and processed meats in the typical food basket were exchanged for quantities of lean, less environmentally harmful meat options (kangaroo, chicken), sustainable fish, nuts and eggs in the H\&S food basket. In the 'grain (cereals)' group, foods made from white grains (rice, pasta, bread) were replaced with wholemeal-based options. Processed cereals (cornflakes, toasted muesli) were replaced with whole rolled oats and wheat-based cereals. In the 'dairy' food group, reduced-fat food items replaced full-fat food items. Orange juice drink is considered a discretionary food due to its high sugar and low juice content in the typical food basket, whereas in the H\&S food basket $100 \%$ orange juice is considered a 'fruit' food due to its $100 \%$ juice content.

The final list of foods for inclusion in the H\&S food basket was created by aggregating all of the foods in the meal plan, resulting in a total of forty-eight foods. The list of foods, and associated quantities, in the typical and H\&S food baskets are shown in Table 2 .

\section{Discussion}

The present study is a contribution to the international call to articulate a H\&S diet ${ }^{(78)}$. We have outlined key health and environmental sustainability principles that can be applied in the selection of foods for inclusion in such a diet; articulated what a sustainable and healthy version of a typical Australian diet might look like; and described a methodology with which to assess the availability and affordability of a H\&S food basket.

There are a small but growing number of analyses internationally that seek to incorporate environmental considerations into diets or dietary guidelines. For example, researchers in the UK have modelled different dietary scenarios, each of which meet nutritional requirements but with different GHG emissions ${ }^{(79)}$. They found that a diet that meets dietary requirements and has lower emissions can be achieved by reducing but not necessarily eliminating meat or dairy products. These dietary changes not only have significant environmental benefits, they can save human lives. Scarborough and colleagues modelled the actual impact on deaths averted as a result of changing diets in order to reduce GHG emissions in the $\mathrm{UK}^{(80)}$.

In our study we used a simple replacement method to compile the H\&S diet. Informed by the evidence (existing LCA) we replaced food items that were typically consumed by the Australian public in each of the five food groups with a comparable food item that had a lower environmental footprint as measured by GHG emissions, water use and biodiversity impact. We applied three overarching principles when developing the H\&S diet: (i) any food that is consumed above a person's energy requirement represents an avoidable environmental burden in the form of GHG emissions, use of natural 
Table 1 Summary of the decision-making logic used in the development of a healthy and sustainable (H\&S) food basket

\begin{tabular}{ll}
\hline & H\&S option \\
\hline Typical food item & \\
\hline Vegetables & Potato \\
Potatoes: potato, sweet potato & Cabbage \\
Brassica vegetables: cabbage, cauliflower & Tomato \\
Fruiting vegetables: tomato, capsicum, & \\
pumpkin, zucchini, squash & Lettuce \\
Leaf and stalk vegetables: lettuce, celery, & \\
rhubarb & Onion, mushroom \\
Other: onion, mushroom, tinned/frozen & \\
vegetables & \\
& \\
& \\
& \\
& \\
& \\
Fruit & \\
Pomme fruit: apple & \\
Citrus fruit: orange, mandarin & \\
Tropical fruit: banana, kiwi & Apple \\
Stone fruit: peach & Orange, mandarin \\
Dried fruit: sultanas, apricot & Banana, kiwi \\
Other fruit: avocado, fig, tinned fruit in & \\
natural juice, tinned fruit in heavy syrup, & Avocado, fig \\
fruit juice 100\% & \\
Grain (cereal) foods & Whole rolled oats \\
White rice & \\
White bread/flat bread & Unbleached flour \\
White pasta & \\
Mixed source: sweetened corn flakes & Brown rice \\
Boasted muesli & \\
& \\
& \\
& \\
& \\
& \\
& \\
&
\end{tabular}

Rationale based on health and environmental evidence

Vegetables viting vegetables: tomato, capsicum,

Cabbage

her: onion, mushroom, tinned/frozen

Onion, mushroom

Unbleached flour
Meats and poultry, fish, eggs, tofu, nuts and seeds, and legumes/beans

Lamb, beef, kangaroo rump steak

Poultry: chicken, breast or drumsticks; chicken, whole; duck, breast or legs

Fish: farmed salmon fillets, local salmon wild, imported salmon wild, Australian salmon, bream, King George whiting and mullet, southern bluefin tuna and jackass morwong, tinned salmon, tinned tuna

Legumes: beans, lentils, tinned beans

Eggs

Nuts

Milk, yoghurt, cheese and/or their alternatives Fresh whole milk

Cheese

Yoghurt, plain

Allowance for unsaturated spreads and oils Margarine
Options that have a lower environmental footprint include kangaroo

Chicken

Australian salmon, bream, King George whiting and mullet

Dry beans, dry lentils

Eggs

Dry roasted, unsalted peanuts

Fresh reduced-fat milk Reduced-fat cheese Yoghurt, plain reduced-fat

Canola oil; olive oil; peanut butter
The vegetable selection in the H\&S diet follows ADG2 more closely, which recommends a variety of types and colours

Fresh vegetables are more environmentally friendly than tinned vegetables

Tinned vegetables can be higher in salt and sugar, are more processed and use more environmental resources

Of the vegetables listed in both columns, potato, cabbage, carrot, tomato, lettuce, onion and mushroom have the lowest $\mathrm{CO}_{2}$ and water impact

While it is recommended to choose a variety of vegetables, tend towards those in the right-hand column for environmental reasons

Fresh fruits are more environmentally friendly than tinned fruit; tinned fruit is more processed and uses more environmental resources

Of all the fruits listed, orange, mandarin, banana, kiwi, avocado and fig have the lowest $\mathrm{CO}_{2}$ and water impact

ADG2 recommends the consumption of wholegrain options of cereal foods where possible

Brown, whole and single-source products are less processed, therefore they are healthier and use less environmental resources than their more processed counterparts

Of all the grains listed, rice has the highest $\mathrm{CO}_{2}$ and water impact

Whole rolled oats are less processed, therefore they are healthier and use less environmental resources than mixed-source, toasted and sweetened cereals

Consume a variety of animal-source foods and alternative products for health

Of all the meats listed, red meat has the highest $\mathrm{CO}_{2}$ and water impact. Animal-source foods with lower environmental impacts are chicken, kangaroo, sustainable fish, legumes, nuts and egg

Fresh fish from stable stocks is more environmentally friendly than tinned fish. Tinned fish can be higher in salt, is more processed and therefore uses more environmental resources

Dry legumes and unsalted nuts have lower $\mathrm{CO}_{2}$ and water impact than tinned or precooked options because of their relative lack of processing and environmental resource usage

ADG2 recommends the consumption of mostly reduced-fat dairy foods and their alternatives

If considering the environment, of the three dairy foods, milk has the lowest $\mathrm{CO}_{2}$ and water impact followed by yoghurt, then cheese

The Australian Guide to Health Eating allows for the consumption of a small amount of unsaturated spreads and oils

Less processed spreads and oils will use fewer natural resources 


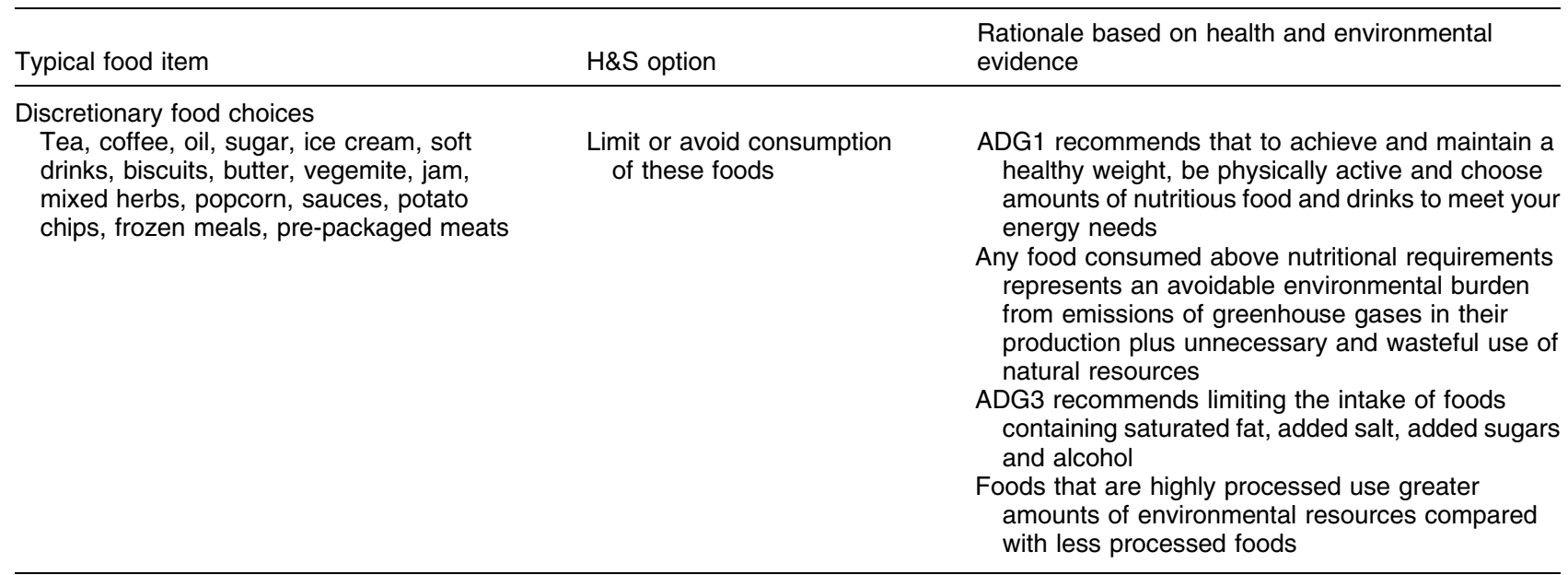

ADG, Australian Dietary Guidelines ${ }^{(8)}$.

resources and pressure on biodiversity; (ii) reducing the consumption of discretionary foods that are energy-dense and highly processed and packaged reduces both the risk of dietary imbalances and the use of environmental resources; and (iii) a diet comprising less animal- and more plant-derived foods delivers both health and ecological benefits.

\section{Limitations}

Much of the environmental impact evidence is based on primary production and on-farm impacts, with less evidence available for other stages in the food supply chain. This can often mean that the interpretation is placed on primary foods in the absence of evidence for processed or highly processed foods. There are limitations to the comparability of findings for some studies, given the often small number of studies per food and the use of different methodological approaches. Despite many studies adopting an LCA approach, there was still a range of methodologies adopted within the LCA model. Some studies might incorporate the environmental impact of manufacturing on-farm machinery, as well as the production of all other on-farm inputs such as fertilizer, while others would only incorporate fertilizer production. As well as inconsistency in the activities of the food system that were assessed, there were also differences in aspects such as data source, units of measurement and definition of variables. The H\&S diet may not be representative of actual eating patterns as the basket was constructed based on the limited numbers of food items where evidence was available.

Despite the difficulties regarding the completeness of the evidence and differing methodologies, clearly the types of food and beverage choices made by people play an important role in ensuring good health and environmental sustainability. We believe there is enough evidence to begin to articulate a H\&S diet, thereby providing guidance to consumers and policy makers concerned for public health, nutrition and environmental sustainability.

However, it is important to emphasize that the whole food system, which involves agricultural production, food processing and packaging, distribution and retail as well as consumption, requires inputs such as land, water and energy and that the outputs along the supply chain contribute to environmental degradation. It is essential therefore that a comprehensive policy response is taken which includes individual responsibility but is not entirely focused on it - policy is needed that addresses the health and environmental aspects of all parts of the food system. We have articulated a H\&S diet not to facilitate 'policy drift' to focus on lifestyle choices, but rather to provide a framework to support cross-sectoral food and health policy discussions, especially in relation to dietary guidelines in Australia.

A number of policy measures are frequently discussed with the aim of decreasing the impact of food production on the environment (including enhanced energy and resource efficiency, improved management approaches, technological improvements and improved productivity) and in order to restore degraded land and water resources ${ }^{(56,81)}$. In the case of GHG emissions in particular, there is a large body of work addressing the mitigation of GHG emissions on-farm and governments around the world have introduced a range of policy measures in order to do this.

In addition to policies addressing the production side of food, there is a growing body of research suggesting that in order to reduce the environmental impacts of food we must also change our food consumption habits, specifically what we eat ${ }^{(6,81,82)}$. In particular, a number of studies have focused on the need to reduce consumption of meat and dairy foods ${ }^{(81)}$. Garnett (2011) considers that a context-specific approach to meat and dairy consumption is required - one that situates livestock farming within a 
Table 2 A typical food basket and a healthy and sustainable (H\&S) food basket

\begin{tabular}{|c|c|c|c|}
\hline \multicolumn{2}{|c|}{ Typical basket } & \multicolumn{2}{|c|}{$\mathrm{H} \& \mathrm{~S}$ basket } \\
\hline Basket item & Total weekly amount & Basket item & Total weekly amount \\
\hline \multicolumn{4}{|l|}{ Vegetables } \\
\hline Carrots (pre-packed) & $225 \mathrm{~g}$ & Carrots (loose) & $1377 \mathrm{~g}$ \\
\hline Cauliflower (pre-packed) & $487 \cdot 5 \mathrm{~g}$ & Cauliflower (loose) & $300 \mathrm{~g}$ \\
\hline Potatoes (pre-packed) & $352 \mathrm{~g}$ & Potatoes (loose) & $740 \mathrm{~g}$ \\
\hline Tomatoes (pre-packed) & $720 \mathrm{~g}$ & Tomatoes (loose) & $1980 \mathrm{~g}$ \\
\hline Lettuce (pre-packed) & $1800 \mathrm{~g}$ & Lettuce (loose) & $900 \mathrm{~g}$ \\
\hline Mushrooms (pre-packed) & $296 \mathrm{~g}$ & Mushroom (loose) & $444 \mathrm{~g}$ \\
\hline Onion (pre-packed) & $315 \mathrm{~g}$ & Onion (loose) & $525 \mathrm{~g}$ \\
\hline Frozen mixed veg & $1160 \mathrm{~g}$ & Cabbage (loose) & $425 \mathrm{~g}$ \\
\hline Pumpkin & $70 \mathrm{~g}$ & Fresh basil & $54 \mathrm{~g}$ \\
\hline Sweet potatoes (pre-packed) & $560 \mathrm{~g}$ & Fresh parsley & $60 \mathrm{~g}$ \\
\hline Tinned green beans & $1980 \mathrm{~g}$ & Celery (loose) & $200 \mathrm{~g}$ \\
\hline Zucchini (pre-packed) & $1179 \mathrm{~g}$ & & \\
\hline \multicolumn{4}{|l|}{ Fruit } \\
\hline Green apples (pre-packed) & $624 \mathrm{~g}$ & Avocado (loose) & $450 \mathrm{~g}$ \\
\hline Peaches (pre-packed) & $1240 \mathrm{~g}$ & Bananas & $900 \mathrm{~g}$ \\
\hline Red apples (pre-packed) & $1480 \mathrm{~g}$ & Kiwi (loose) & $624 \mathrm{~g}$ \\
\hline Tinned fruit salad & $1020 \mathrm{~g}$ & Mandarin (loose) & $320 \mathrm{~g}$ \\
\hline Dried sultanas & $340 \mathrm{~g}$ & Oranges (loose) & $1920 \mathrm{~g}$ \\
\hline & & $100 \%$ orange juice & $3668 \mathrm{ml}$ \\
\hline \multicolumn{4}{|l|}{ Grain (cereal) foods } \\
\hline Cornflakes & $594 \mathrm{~g}$ & Weetbix & $2250 \mathrm{~g}$ \\
\hline Muesli & $2880 \mathrm{~g}$ & Whole rolled oats & $2280 \mathrm{~g}$ \\
\hline White bread (pre-packed) & $6080 \mathrm{~g}$ & Wholemeal bread, fresh & $7474 \mathrm{~g}$ \\
\hline Turkish bread (pre-packed) & $340 \mathrm{~g}$ & Fresh Turkish bread & $1020 \mathrm{~g}$ \\
\hline White rice & $8200 \mathrm{~g}$ & Brown rice & $5970 \mathrm{~g}$ \\
\hline White flour & $33.6 \mathrm{~g}$ & Wheat flour & $44.8 \mathrm{~g}$ \\
\hline White pasta & $520 \mathrm{~g}$ & Couscous & $1850 \mathrm{~g}$ \\
\hline & & Wholemeal pasta & $5760 \mathrm{~g}$ \\
\hline \multicolumn{4}{|c|}{ Meats and poultry, fish, eggs, tofu, nuts and seeds, and legumes/beans } \\
\hline Chicken breast & $680 \mathrm{~g}$ & Chicken breast & $1360 \mathrm{~g}$ \\
\hline Beef steak & $400 \mathrm{~g}$ & Kangaroo & $400 \mathrm{~g}$ \\
\hline Lamb chops & $368 \mathrm{~g}$ & Australian salmon & $560 \mathrm{~g}$ \\
\hline Minced beef & $400 \mathrm{~g}$ & Dry lentils & $400 \mathrm{~g}$ \\
\hline Sliced ham & $210 \mathrm{~g}$ & Unsalted almonds & $320 \mathrm{~g}$ \\
\hline Eggs & $472 \mathrm{~g}$ & Eggs (free range) & $826 \mathrm{~g}$ \\
\hline \multicolumn{4}{|c|}{ Milk, yoghurt, cheese and/or their alternatives } \\
\hline Cheddar cheese & $630 \mathrm{~g}$ & Reduced-fat cheese & $1188 \mathrm{~g}$ \\
\hline Milk, whole & $8250 \mathrm{ml}$ & Reduced-fat milk & $8750 \mathrm{ml}$ \\
\hline Yoghurt & $3200 \mathrm{~g}$ & Reduced-fat yoghurt & $3600 \mathrm{~g}$ \\
\hline \multicolumn{4}{|c|}{ Allowance for unsaturated spreads and oils } \\
\hline Margarine & $144 \mathrm{~g}$ & Canola oil & $120 \mathrm{ml}$ \\
\hline & & Olive oil & $80 \mathrm{ml}$ \\
\hline & & Peanut butter & $56 \mathrm{~g}$ \\
\hline \multicolumn{4}{|l|}{ Discretionary food choices } \\
\hline Butter & $320 \mathrm{~g}$ & & \\
\hline Chicken stock & $5 \mathrm{~g}$ & & \\
\hline Coca Cola & $2400 \mathrm{ml}$ & & \\
\hline Frozen fish sticks & $320 \mathrm{~g}$ & & \\
\hline Frozen meat pie & $1520 \mathrm{~g}$ & & \\
\hline Frozen pizza & $1040 \mathrm{~g}$ & & \\
\hline Ice cream & $899 \mathrm{ml}$ & & \\
\hline Lamington biscuit & $300 \mathrm{~g}$ & & \\
\hline Mayonnaise & $240 \mathrm{~g}$ & & \\
\hline Orange juice drink & $3626 \mathrm{ml}$ & & \\
\hline Potato chips & $88 \mathrm{~g}$ & & \\
\hline Sugar, white & $28 \mathrm{~g}$ & & \\
\hline Tinned spaghetti & $1590 \mathrm{~g}$ & & \\
\hline Tomato soup & $880 \mathrm{~g}$ & & \\
\hline Chicken stock & $10 \mathrm{~g}$ & & \\
\hline Jam & $104 \mathrm{~g}$ & & \\
\hline Popcorn & $135 \mathrm{~g}$ & & \\
\hline Worcester sauce & $20 \mathrm{~g}$ & & \\
\hline
\end{tabular}

Based on the average weekly intake of a household of four: an adult male (aged 19-60 years), an adult female (aged 19-60 years), a boy aged 15 years and a girl aged 4 years.

Recommended daily servings based on the Australian Dietary Guidelines and the Australian Guide to Healthy Eating. 
policy framework that integrates agricultural, environmental and nutritional goals. Other approaches suggested, often controversially, for developed world populations include: (i) reducing food consumption in overweight populations; (ii) cutting food waste; (iii) consuming more seasonal food; (iv) reducing consumption of 'unnecessary' foods; (v) shopping for food on the Internet; and (vi) taking the time to plan when food shopping ${ }^{(81)}$. The practicalities of enabling consumers to make different choices are complex, with research into how changes in behaviour might be achieved still being in its infancy ${ }^{(81)}$.

\section{Acknowledgements}

Sources of funding: This research received support from the Climate and Health Cluster which is funded by the CSIRO (Commonwealth Scientific and Industrial Research Organization) Flagship Collaboration Fund. Conflicts of interest: The authors have no conflicts of interest. Ethics: Ethical approval was not required. Authors' contributions: S.F. was responsible for the conceptual development of the study and did the first complete draft of the manuscript. L.J.B. and M.L. both contributed to the conceptual development of the study and inputted into each draft of the paper.

\section{References}

1. McMichael A (2001) Impact of climatic and other environmental changes on food production and population health in the coming decades. Proc Nutr Soc 60, 195-201.

2. Friel S, Marmot M, McMichael A et al. (2008) Global health equity and climate stabilisation - need for a common agenda. Lancet 372, 1677-1683.

3. Friel S (2010) Climate change, food insecurity and chronic diseases: sustainable and healthy policy opportunities for Australia. NSW Public Health Bull 21, 129-133.

4. Coveney J (2000) Food security and sustainability: are we selling ourselves short? Asia Pac J Clin Nutr 9, 97-100.

5. Tapsell L, Probst Y, Lawrence M et al. (2011) Food and nutrition security in the Australia-New Zealand region: impact of climate change. World Rev Nutr Diet 102, 192-200.

6. McMichael A, Powles J, Butler C et al. (2007) Food, livestock production, energy, climate change and health. Lancet 370, 55-65.

7. National Health and Medical Research Council (2013) Eat for Health: Educator Guide. Canberra: NHMRC.

8. National Health and Medical Research Council (2013) Australian Dietary Guidelines. Canberra: NHMRC.

9. Burlingame B \& Dernini S (2011) Sustainable diets: the Mediterranean diet as an example. Public Health Nutr 14, 2285-2287.

10. Mithril C, Dragsted LO, Meyer C et al. (2012) Guidelines for the new Nordic diet. Public Health Nutr 15, 1941-1947.

11. Food and Agriculture Organization of the United Nations (2012) Sustainable Diets and Biodiversity. Directions and Solutions for Policy, Research and Action. Rome: FAO.

12. Mozaffarian D \& Ludwig DS (2010) Dietary guidelines in the 21st century: a time for food. JAMA 304, 681-682.

13. Yngve A \& Tseng M (2010) Dietary guidelines and goalsetting. Public Health Nutr 13, 1149-1150.
14. Holdsworth M (2010) Sustainability should be integral to nutrition and dietetics. J Hum Nutr Diet 23, 467-468.

15. National Food Administration (2009) The National Food Administration's Environmentally Effective Food Choices: Proposal Notified to the EU. Stockholm: National Food Administration.

16. Kickbusch I (2010) The Food System: A Prism of Present and Future Challenges for Health Promotion and Sustainable Development. Bern/Lausanne: Health Promotion Switzerland.

17. Cabinet Office (2008) Food Matters: Towards a Strategy for the 21st Century. London: Strategy Unit, Cabinet Office, UK Government.

18. The Prime Minister's Science, Engineering and Innovation Council (2010) Australia and Food Security in a Changing World. Canberra: PMSEIC.

19. Department of Agriculture, Fisheries and Forestry (2012) National Food Plan Green Paper 2012. Canberra: DAFF.

20. United Nations Environment Programme (2010) Year Book 2010: New Science and Developments in our Changing Environment. Nairobi: UNEP.

21. Food and Agriculture Organization of the United Nations (2006) The State of Food Insecurity in the World 2006. Rome: FAO.

22. United Nations Development Programme (2007) Human Development Report: Fighting Climate Change: Human Solidarity in a Divided World. New York: UNDP.

23. Department of Climate Change and Energy Efficiency (2012) Australian National Greenhouse Accounts: National Inventory by Economic Sector, 2009-10. Canberra: DCCEE.

24. Wood R, Lenzen M, Dey C et al. (2006) A comparative study of some environmental impacts of conventional and organic farming in Australia. Agric Syst 89, 324-348.

25. Australian Bureau of Statistics (2006) Water Account, Australia, 2004-05. Canberra: ABS.

26. Department of Sustainability, Environment, Water, Population and Communities (2011) State of the Environment 2011. Canberra: The Department of Sustainability, Environment, Water, Population and Communities.

27. Bethune M \& Armstrong DP (2004) Overview of the irrigated dairy industry in Australia. Aust J Exp Agric 44, $127-129$.

28. Bird PR (2003) Sustainable Systems of Dairy Production: A Review of Water Quality, Biodiversity, Soil Salinity/Acidity, Farm Forestry, Shade/Shelter and Productivity Issues, and the Likely Impact on These of Revegetation of Dairy Farms. Hamilton, VIC: Pastoral and Veterinary Institute.

29. Khan S, Abbas A, Rana T et al. (2010) Dairy Water Use in Australian Dairy Farms: Past Trends and Future Prospects. Melbourne, VIC: CSIRO Water for a Healthy Country National Research Flagship.

30. Biswas WK, Barton L \& Carter D (2008) Global warming potential of wheat production in Western Australia: a life cycle assessment. Water Environ J 22, 206-216.

31. Ridoutt BG, Eady SJ, Sellahewa J et al. (2009) Water footprinting at the product brand level: case study and future challenges. J Clean Prod 17, 1228-1235.

32. Larsen K, Ryan C \& Abraham AB (2008) Sustainable and Secure Food Systems for Victoria: What Do We Know? What Do We Need to Know? Melbourne, VIC: Victorian Eco-Innocation Lab (VEIL), University of Melbourne.

33. Bradbear C \& Friel S (2011) Food Systems and Environmental Sustainability: A Review of the Australian Evidence. NCEPH Working Paper. Canberra: The Australian National University.

34. Lobell DB, Burke MB, Tebaldi C et al. (2008) Prioritizing climate change adaptation needs for food security in 2030. Science 319, 607-610.

35. Australian Marine Conservation Society (2011) Seafood Guide. Brisbane, QLD: AMCS. 
36. Friel S, Dangour AD, Garnett T et al. (2009) Public health benefits of strategies to reduce greenhouse-gas emissions: food and agriculture. Lancet 374, 2016-2025.

37. Food and Agriculture Organization of the United Nations (2008) The State of Food Insecurity in the World, 2008: High Food Prices and Food Security: Threats and Opportunities. Rome: FAO.

38. Health Council of the Netherlands (2011) Guidelines for $A$ Healthy Diet: The Ecological Perspective. The Hague: Health Council of the Netherlands.

39. Monteiro C (2010) The big issue is ultra-processing (Commentary). World Nutr 1, 237-269.

40. Blue Mountains City Council (2009) Healthy and Sustainable Food Choices. http://www.sustainablebluemountains.net.au/ imagesDB/resources/BMCChealthysustainablefoodguide.pdf (accessed May 2013).

41. Barilla Center for Food and Nutrition (2011) Double Pyramid 2011: healthy diet for all and environmentally sustainability. http://www.barillacfn.com/wp-content/uploads/2012/07/ en_PositionPaper-BarillaCFN_DP.pdf (accessed May 2013).

42. Monteiro CA, Levy RB, Claro RM et al. (2011) Increasing consumption of ultra-processed foods and likely impact on human health: evidence from Brazil. Public Health Nutr 14, 5-13

43. Maraseni TN, Cockfield G, Maroulis J et al. (2010) An assessment of greenhouse gas emissions from the Australian vegetables industry. J Environ Sci Health B 45, 578-588.

44. Australian Bureau of Statistics (2010) Water Use on Australian Farms 2008-09. Canberra: ABS.

45. Ashcroft B, Boland A, Csaky D et al. (2005) Benchmarking Vegetable Industry Water Use. Final Report HAL Project VGO4015. Melbourne, VIC and Sydney, NSW: Department of Primary Industries, Victoria and Horticulture Australia Limited.

46. Henderson C (2006) Maximising Returns from Water in the Australian Vegetable Industry: Queensland. Orange, NSW: NSW Department of Primary Industries.

47. Hickey M \& Hoogers R (2006) Maximising Returns from Water in the Australian Vegetable Industry: New South Wales. Orange, NSW: NSW Department of Primary Industries.

48. Hickey M, Hoogers R, Singh R et al. (2006) Maximising Returns from Water in the Australian Vegetable Industry: National Report. Orange, NSW: NSW Department of Primary Industries.

49. Hoffmann H, Phillips D \& Paulin B (2005) Maximising Returns from Water in the Australian Vegetable Industry: Western Australia. Orange, NSW: NSW Department of Primary Industries.

50. O'Donnell D (2006) Maximising Returns from Water in the Australian Vegetable Industry: Tasmania. Orange, NSW: NSW Department of Primary Industries.

51. Sylvia S \& Skewes M (2006) Maximising Returns from Water in the Australian Vegetable Industry: South Australia. Orange, NSW: NSW Department of Primary Industries.

52. Top M \& Ashcroft B (2005) Maximising Returns from Water in the Australian Vegetable Industry: Victoria. Orange, NSW: NSW Department of Primary Industries.

53. Ridoutt BG, Juliano P, Sanguansri P et al. (2010) The water footprint of food waste: case study of fresh mango in Australia. I Clean Prod 18, 1714-1721.

54. Barraclough \& Co (1999) Audit of Water and Irrigation Use Efficiencies on Farms within the Queensland Horticultural Industry. Sydney, NSW: Barraclough \& Co.

55. Foran B, Lenzen M \& Dey C (2005) Balancing Act: A Triple Bottom Line Analysis of the Australian Economy. Canberra: CSIRO and the University of Sydney.

56. Khan S, Khan MA, Hanjra MA et al. (2009) Pathways to reduce the environmental footprints of water and energy inputs in food production. Food Policy 34, 141-149.
57. Ridoutt B \& Poulton P (2009) SAI Platform Australia Water Footprint Pilot Project: Wheat, Barley and Oats Grown in the Australian State of New South Wales: Summary Report. Melbourne, VIC: CSIRO National Research Flagships: Sustainable Agriculture.

58. Biswas WK, Graham J, Kelly K et al. (2010) Global warming contributions from wheat, sheep meat and wool production in Victoria, Australia - a life cycle assessment. J Clean Prod 18, 1386-1392.

59. Humphreys E, Lewin LG, Khan S et al. (2006) Integration of approaches to increasing water use efficiency in rice-based systems in southeast Australia. Field Crops Res 97, 19-33.

60. Garnaut R (2006) The Garnaut Climate Change Review. Canberra: Australian National University.

61. Peters GM, Rowley HV, Wiedemann S et al. (2010) Red meat production in Australia: life cycle assessment and comparison with overseas studies. Environ Sci Technol 44, 1327-1332.

62. Wiedemann S, McGahan E, Grist S et al. (2010) Environmental Assessment of Two Pork Supply Chains using Life Cycle Assessment. Canberra: Rural Industries Research and Development Corporation.

63. Wilson GR \& Edwards MJ (2008) Native wildlife on rangelands to minimise methane and produce loweremission meat: kangaroos versus livestock. Conservation Lett 1, 119-128.

64. Peters GM, Wiedemann SG, Rowley HV et al. (2010) Accounting for water use in Australian red meat production. Int J Life Cycle Assess 15, 311-320.

65. Williams JE \& Price RJ (2010) Impacts of red meat production on biodiversity in Australia: a review and comparison with alternative protein production industries. Anim Prod Sci 50, 723-747.

66. Wilson D, Curtotti R \& Vieira S (2010) Overview. In Fishery Status Reports 2009, pp. 1-56 [D Wilson, R Curtotti and G Begg, editors]. Canberra: Australian Bureau of Agricultural and Resource Economics, Bureau of Rural Sciences.

67. Dairy Australia (2006) Australian Dairy Manufacturing Industry State of the Environment Report. Canberra: Dairy Manufacturers Sustainability Council.

68. Dairy Australia (2008) Australian Dairy Manufacturing Industry Sustainability Report 2007-08. Canberra: Dairy Manufacturers Sustainability Council.

69. Martin Stewardship and Management Strategies Pty Ltd \& Perchards Ltd (2008) The Status of Packaging Sustainability in Australia: Final Report. Turramurra, NSW and St Albans, UK: MS2 and Perchards.

70. Chen G, Orphant S, Kenman SJ et al. (2005) Life cycle assessment of a representative dairy farm with limited irrigation pastures. Presented at the 4th Australian Conference on Life Cycle Assessment, Sydney, Australia, 23-25 February 2005.

71. Christie K, Rawnsley R \& Donaghy D (2008) Whole Farm System Analysis of Greenhouse Gas Emission Abatement Strategies for Dairy Farms: Final Report to Dairy Australia on the Investigation and Analysis into Greenhouse Gas Abatement Strategies, Modelling and Decision Tools for the Australian Dairy Industry. Hobart, TAS: Tasmanian Institute of Agricultural Research, University of Tasmania.

72. Feitz AJ, Lundie S, Dennien G et al. (2007) Generation of an industry-specific physico chemical allocation matrix: application in the dairy industry and implications for systems analysis. Int J Life Cycle Anal 12, 107-119.

73. Burns K, Hubay S, King B et al. (2010) Nutritious Food Basket Guidance Document. Published for thw Ministry of Health Promotion. Ontario: Queen's Printer for Ontario.

74. Friel S, Walsh O \& McCarthy D (2006) The irony of a rich country: issues of financial access to and availability of healthy food in the Republic of Ireland. I Epidemiol Community Health 60, 1013-1019. 
75. Queensland Health (2000) The Healthy Food Access Basket Survey 2000. Brisbane, QLD: Queensland Health, Queensland Government.

76. Landrigan T \& Pollard C (2010) Food Access and Cost Survey (FACS) Western Australia. Perth, WA: Department of Health, Government of Western Australia.

77. Northern Territory Government (2007) Northern Territory Market Basket Survey. Darwin, NT: Department of Health and Community Services, Northern Territory Government.

78. Lang $T$ (2012) Sustainable diets and biodiversity: the challenge for policy, evidence and behaviour change. In Sustainable Diets and Biodiversity. Directions and Solutions for Policy, Research and Action, pp. 20-26 [B Burlingame and S Dernini, editors]. Rome: FAO.
79. Macdiarmid JI, Kyle J, Horgan GW et al. (2012) Sustainable diets for the future: can we contribute to reducing greenhouse gas emissions by eating a healthy diet? $\mathrm{Am} J$ Clin Nutr 96, 632-639.

80. Scarborough P, Allender S, Clarke D et al. (2012) Modelling the health impact of environmentally sustainable dietary scenarios in the UK. Eur J Clin Nutr 66, 710-715.

81. Garnett $\mathrm{T}$ (2011) Where are the best opportunities for reducing greenhouse gas emissions in the food system (including the food chain)? Food Policy 36, Suppl. 1, S23-S32.

82. Deckers J (2010) Should the consumption of farmed animal products be restricted, and if so, by how much? Food Policy 35, 497-503. 